\title{
Modeling of application the FACTS devices on the example of power system of United Power System of Center
}

\author{
Alexey Udaratin ${ }^{1, *}$, Kirill Loginov ${ }^{1}$, Timur Akhmetov $^{2}$ and Alexandr Nemirovskiy ${ }^{1}$ \\ ${ }^{1}$ Vologda State University, Lenina Street 15, Vologda, 160000 Russia \\ ${ }^{2}$ Kazan State Power Engineering University, Kazan, Russia
}

\begin{abstract}
This paper considers installation of a flexible AC transmission system (FACTS) device on the $500 \mathrm{kV}$ line of substation (SS) Belozerskaya - SS Vologodskaya of the United Power System of Center. Three FACTS devices in normal operation mode were modeled: a static reactive power compensator (STATCOM), a static synchronous series compensator, and a unified power flow control system. The obtained results are summarized in Table, which substantiates the choice of the best compensation for the Belozerskaya - Vologodskaya line.
\end{abstract}

\section{Introduction}

Development of electric power complex is one of the most important tasks of the Russian Federation nowadays. Every year, the demand for electricity is becoming higher. A growing number of new houses, shopping centers, hospitals are connected to substations that transmit energy to all corners of the country. But transmission of energy flows has some troubles. Some part of energy is lost during transmission, which includes:

1) Losses of technical nature. They arise during energy transmission via electric networks and are caused by physical processes that occur in wires and equipment.

2) Electrical energy, which is spent for operation of substations and personnel. This energy is assessed by meters installed on auxiliary transformers of energy plants.

3) Losses, which are caused by errors during its measurement [1].

The first item accounts for the highest electrical energy consumption, since reactive power arises in wires during transmission, and its loss is greater for the longer line. But this problem can be solved if one includes devices that compensate it during undervoltage or overvoltage in the line. The flexible AC transmission systems (FACTS) [2] are the devices, which over the past 20 years are acknowledged to provide the necessary steps for successful compensation of power and voltage.

FACTS devices are divided into two generations: the first and the second. The first-generation devices include shunt reactors (ShR), static capacitor banks (SCB), series compensation devices (SCD), static compensators (SC). The second generation devices include synchronous static compensators (STATCOM), static synchronous series compensators (SSSC), unified power flow control systems (UPFC), phase-shifting devices (PSD), and others.

Over the past 20 years, the second-generation devices were installed on new substations or replaced the existing first-generation devices. STATCOM, SSSC and UPFC are the most widespread devices. They differ among themselves by the installation method: the static synchronous compensator is installed in shunt, the static synchronous series compensator is installed in series with the line, the unified power flow control system is placed universally (namely, in both ways).

Series compensation of reactive power is usually carried out using a static synchronous series compensator. It is attributed to the second generation of FACTS and allows one to withdraw the shortcomings of a thyristor-controlled capacitor bank. SSSC is a static synchronous generator that operates without external energy source as a compensator, the voltage of which is squared relative to the linear one. Static synchronous compensator allows one to use the rated energy of device or absorb power to improve the dynamic component of power system by additional temporary compensation of power to increase or decrease the voltage drop in the line. Energy distribution using SSSC uses the Dynamic Voltage Restorer (DVR) principle. It is aimed to maintain the network in relation to its most vulnerable consumers under short-term disturbances. The power of commercially available DVR installations does not exceed 1 MVA. SSSC is similar to STATCOM, but the alternating voltage output is brought in series with the line. SSSCs are series-connected FACTS devices based on a converter based on voltage source and they can be considered as a perfect type of series compensation, in a similar way STATCOM is more advanced equipment than static reactive-power compensator. [3]

Reactive shunt compensation is mainly carried out by the STATCOM device. Since it belongs to a type of

* Corresponding author: alexu79@mail.ru 


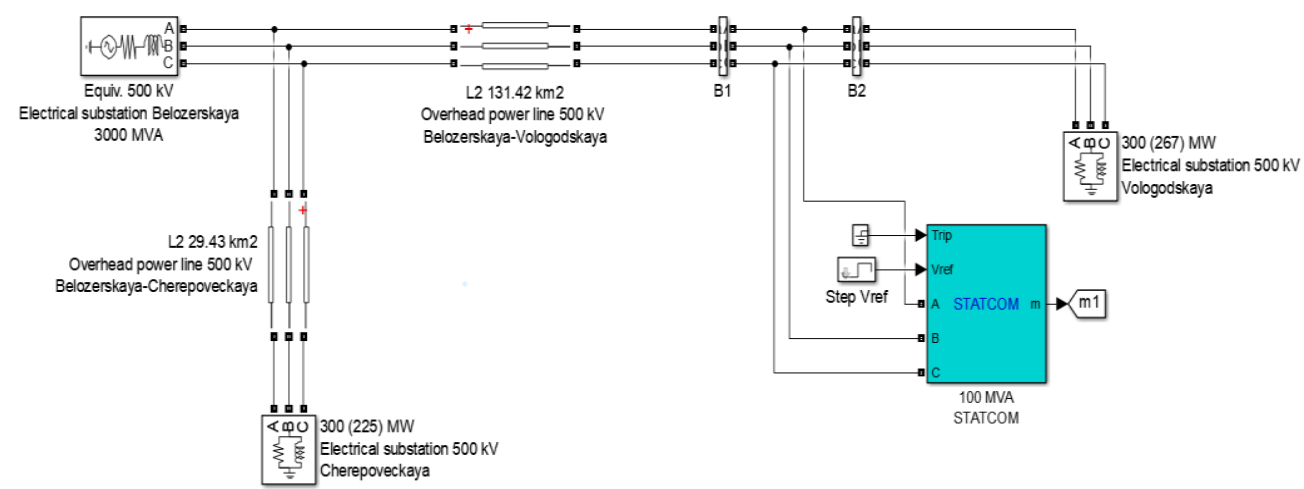

Fig. 1. Model of $500 \mathrm{kV}$ SS Belozerskaya - SS Vologodskaya power system with STATCOM device.

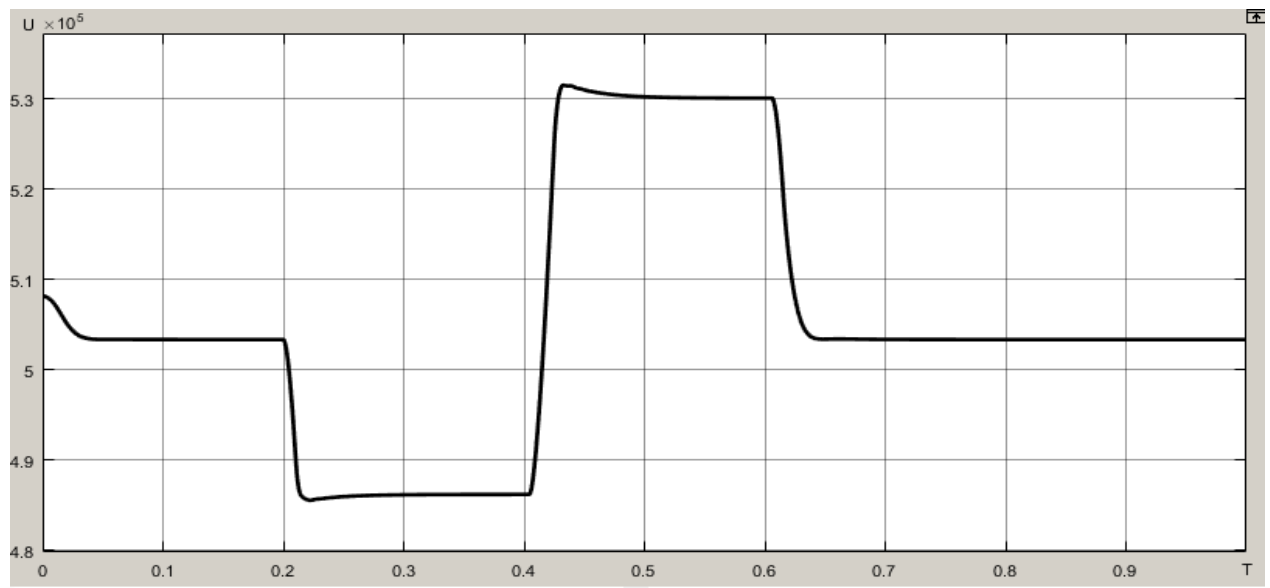

Fig. 2. Voltage on bus B1 with STATCOM device. $\mathrm{U}$ is voltage on line, $\mathrm{T}$ is device operation time.

serial compensators, this device can provide instantaneous reactive power in response to voltage of response to vibrations, STATCOM can also be used as an active harmonic filter.

Universal compensation is a combination of STATCOM and SSSC, which are interconnected by DC link. This allows power to flow from the output of one device to the output of another. Each of its parts consists of transformer and electric converter, which have a joint DC capacitor. Using angular infinite sequential introduction of voltage, UPFC can simultaneously or selectively control voltage, transmission line angle, resistance or active and reactive power [4].

The electric power industry in Russia needs the newest tools to control and transmit electric power over vast distances through existing lines with the smallest financial cost for their modernization, so the present work is of high relevance.

The aim of this work is to model various types of FACTS compensation devices on the line and to select the best one for installation on the line of the United Power System of Center. These includes the following tasks:

1) To model a power line and analyze its output active and reactive power, as well as voltage.

2) To calculate and model the line with FACTS compensation devices.
3) To make a conclusion on the use of a particular type of compensation to improve power transmission on the line and choose the best one.

Modeling was carried out using the MATLAB Simulink program, the effectiveness of which was previously tested on another power system [3]. The 500 $\mathrm{kV}$ line SS Belozerskaya - SS Vologodskaya of UPS Center was selected to install the devices.

\section{FACTS Modeling}

\subsection{STATCOM Modeling}

The power system SS Belozerskaya - SS Vologodskaya with STATCOM device is shown in Fig. 1. Voltage in the line with the device switched on is shown in Fig. 2. The change in flows of active (P, MW, solid line) and reactive power ( $\mathrm{Q}$, Mvar, dashed line) in power system with the device is shown in Fig. 3.

Consider a time interval equal to $\mathrm{t}=1 \mathrm{~s}$. At $\mathrm{t}=0-0.2 \mathrm{~s}$ and $\mathrm{t}=0.6-1 \mathrm{~s}$, STATCOM is switched off. At $\mathrm{t}=0.2-0.6 \mathrm{~s}$ STATCOM is switched on and connected to the network

The modeling results are presented in Table 1.

Analysis of graphs and tables shows that STATCOM operates in two modes: 
Table 1. Change in U, Q and P on bus B1 with STATCOM device.

\begin{tabular}{|l|c|c|c|c|}
\hline STATCOM operation mode & $\mathbf{t}, \mathbf{s}$ & $\mathbf{U}, \mathbf{k V}$ & $\mathbf{Q}, \mathbf{M v a r}$ & $\mathbf{P}, \mathbf{M W}$ \\
\hline Switched off & $\begin{array}{c}\mathrm{t}=0-0.2 \\
\mathrm{t}=0.6-1\end{array}$ & 506 & 215 & 275 \\
\hline Undervoltage mode & $\mathrm{t}=0.2-0.4$ & 487 & 276 & 254 \\
\hline Overvoltage mode & $\mathrm{t}=0.4-1$ & 530 & 105 & 302 \\
\hline
\end{tabular}

1) At undervoltage in the network, STATCOM increases the reactive power flow in it, while compensating the losses (it works as an inductive load);

2) At overvoltage, it reduces the reactive power flow and increases the generation of active power flow, while compensating its shortage [5].

\subsection{SSSC Modeling}

SSSC connected in series to the Belozerskaya Vologodskaya line is shown in Fig. 4. Static synchronous series compensator, unlike STATCOM, is connected to the power line itself. SSSC also has a POD Controller, which consists of an active power measuring system, a low-pass filter, a high-pass filter and a surge suppressor [6].
At $\mathrm{t}=0-0.2 \mathrm{~s}, \mathrm{SSSC}$ is switched off. At $\mathrm{t}=0.2-1 \mathrm{~s}$ SSSC is in operation. The modeling results are presented in Table 2.

A static synchronous series compensator can serve as a generator or consumer of reactive power, without requiring an extra power source. SSSC also allows one to simulate active and reactive power to compensate losses in the line, as well as to spend it for auxiliary power supply system, without affecting the voltage. It can be seen from Fig.5 that when active power decreases by $\mathrm{t}=0.2-0.6 \mathrm{~s}$ or increases by $\mathrm{t}=0.6-1 \mathrm{~s}$, voltage almost does not change [7]. Its basic principle of operation is similar to that of STATCOM. When active power decreases, SSSC compensates it by reactive power and vice versa, which is seen in Fig. 6.

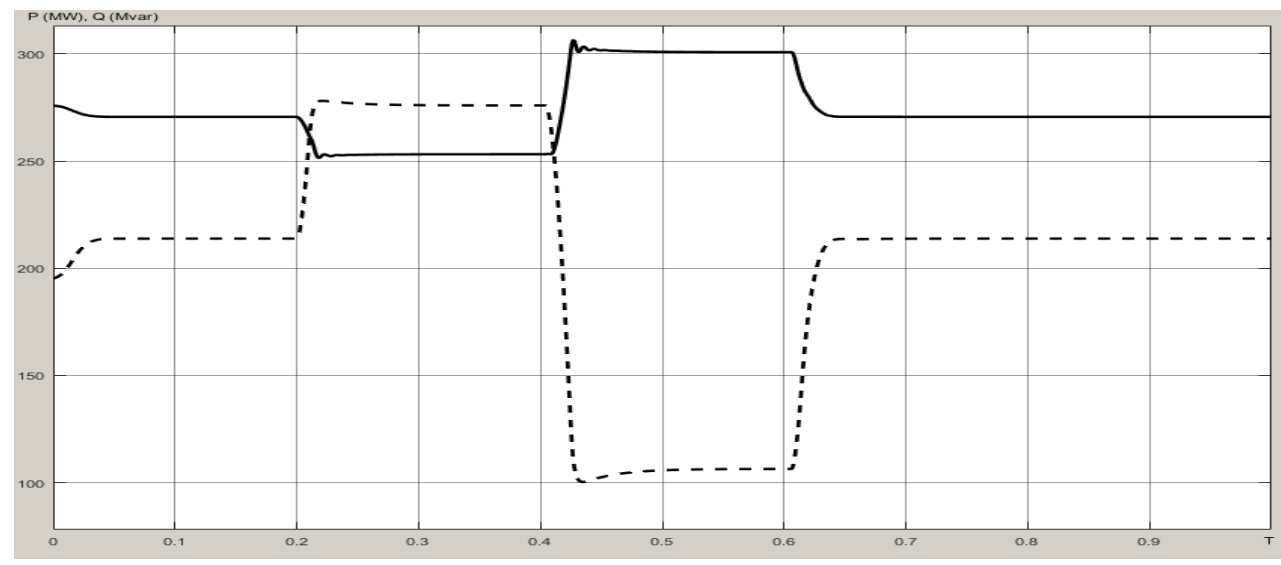

Fig. 3. Active and reactive power of line on the B1 bus in the normal STATCOM mode. P is active power, shown by solid line, $\mathrm{Q}$ is reactive power, shown by dashed line, $\mathrm{T}$ is device operation time.

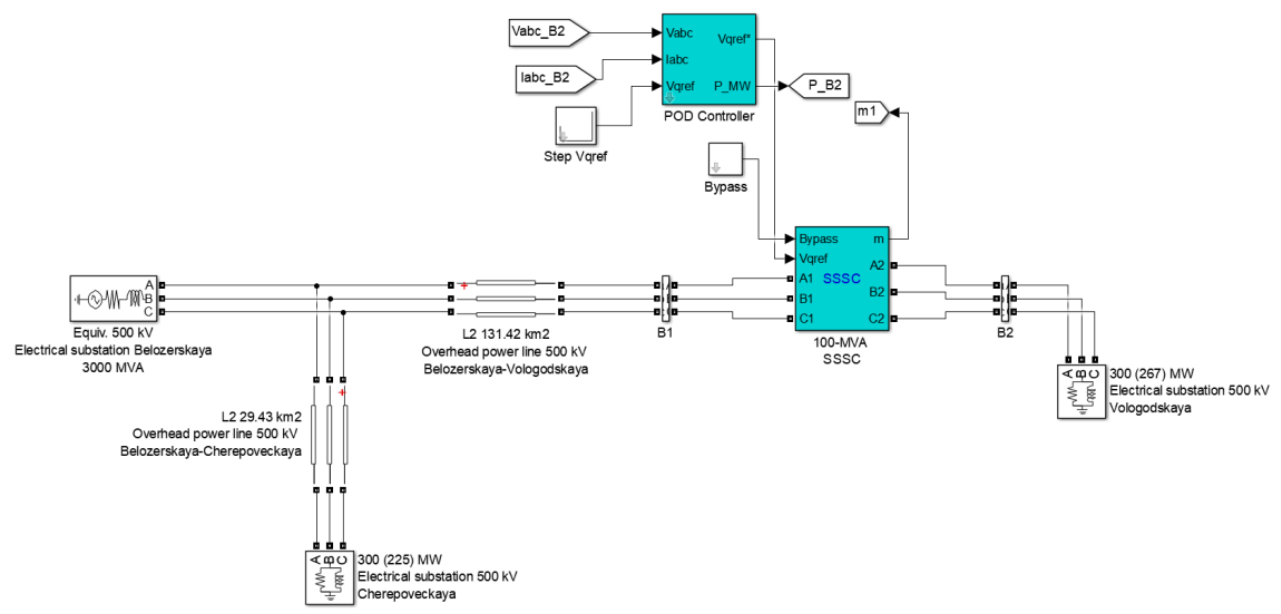

Fig. 4. Model of $500 \mathrm{kV}$ SS Belozerskaya - SS Vologodskaya power system with SSSC device. 
Table 2. Change in U, Q and P on bus B1 with SSSC device.

\begin{tabular}{|l|c|c|c|c|}
\hline SSSC operation mode & $\mathbf{t}, \mathbf{s}$ & $\mathbf{U}, \mathbf{k V}$ & $\mathbf{Q}$, Mvar & P, MW \\
\hline Switched off & $\mathrm{t}=0-0.2$ & 508.5 & 196 & 275 \\
\hline Undervoltage mode & $\mathrm{t}=0.2-0.6$ & 508.3 & 204 & 250 \\
\hline Overvoltage mode & $\mathrm{t}=0.6-1$ & 509 & 187 & 302 \\
\hline
\end{tabular}

Table 3. Change in U, Q and P on bus B1 with UPFC device.

\begin{tabular}{|l|c|c|c|c|}
\hline UPFC operation mode & $\mathbf{t}, \mathbf{s}$ & $\mathbf{U}, \mathbf{k V}$ & $\mathbf{Q}, \mathbf{M v a r}$ & $\mathbf{P}, \mathbf{M W}$ \\
\hline Switched off & $\mathrm{t}=0$ & 516 & 210 & 276 \\
\hline Undervoltage mode & $\mathrm{t}=0-0.5$ & 493 & 215 & 270 \\
\hline
\end{tabular}

\subsection{UPFC Modeling}

Fig. 7 shows a power network model with UPFC. The unified power flow control system consists of SSSC and
STATCOM, interconnected by a DC power line.

At $\mathrm{t}=0-0.5 \mathrm{~s}$, the device operates in undervoltage mode, at $\mathrm{t}=0.5-1 \mathrm{~s}$, voltage in the system increases. The modeling results are presented in Table 3 .

Capacitance of power storage of a DC capacitor is usually small. So, SSSC must receive (or give) active

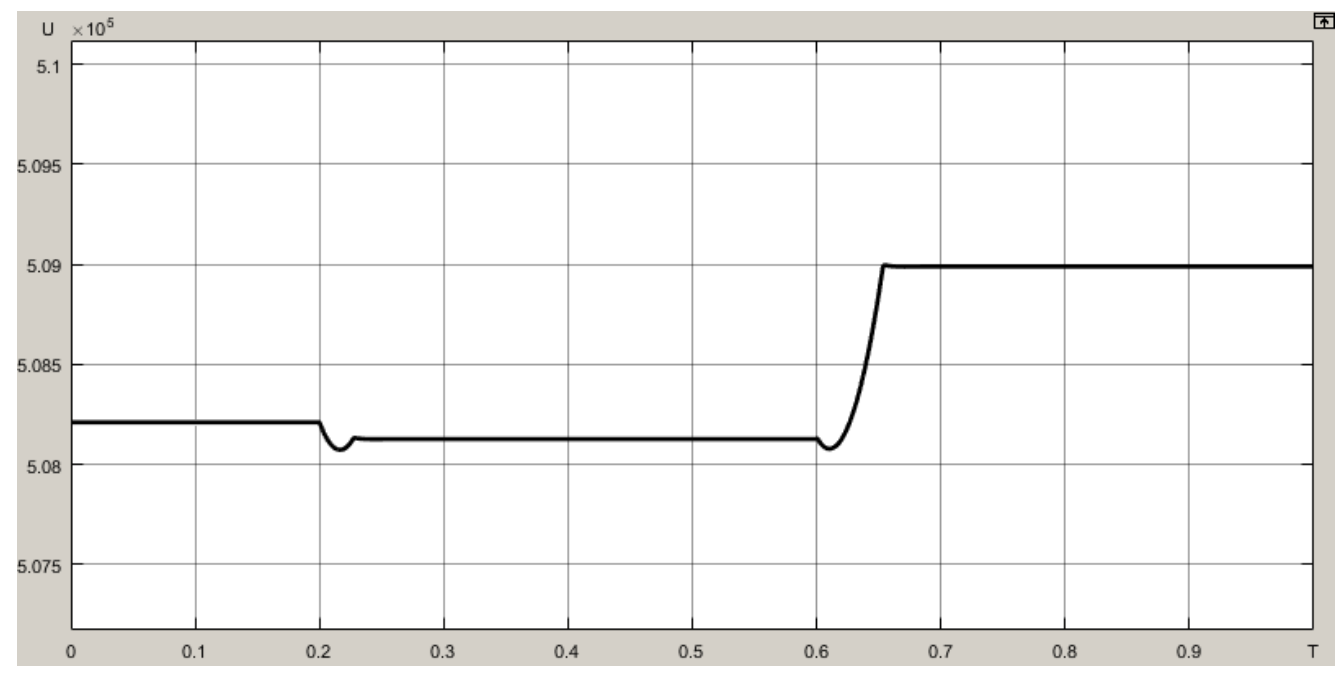

Fig. 5. Voltage on bus B1 with SSSC device. $\mathrm{U}$ is voltage on line, $\mathrm{T}$ is device operation time.

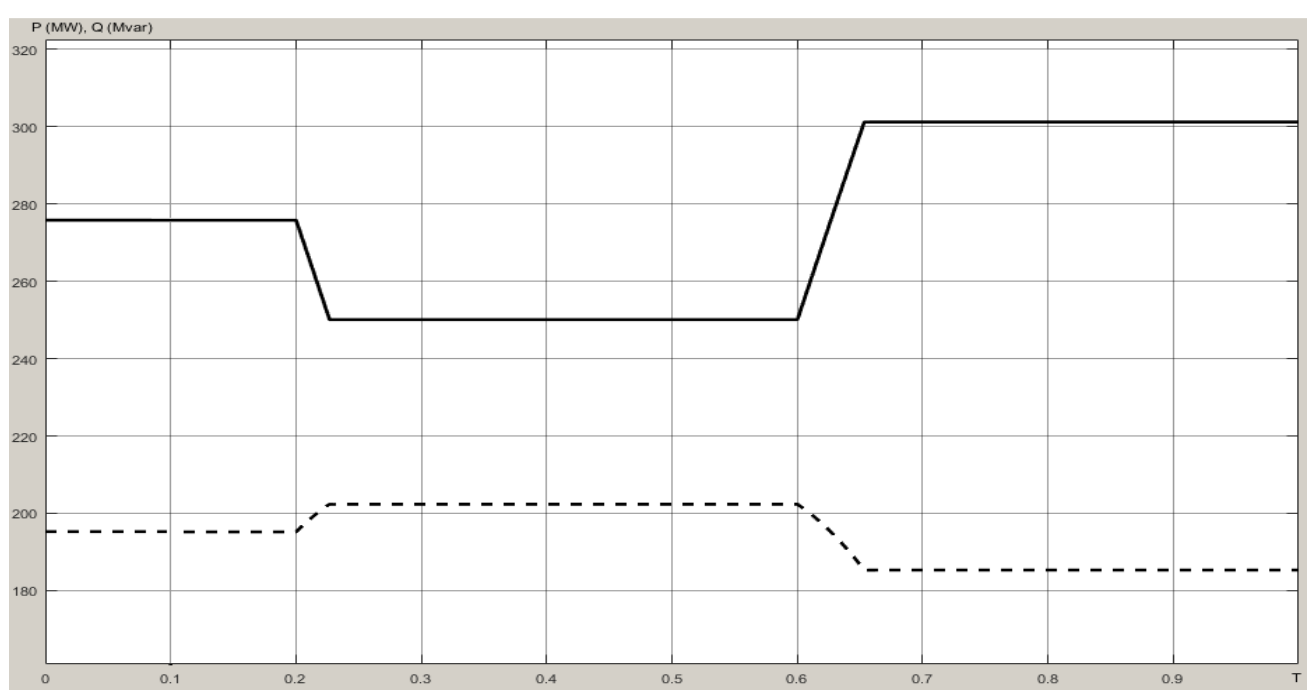

Fig. 6. Active and reactive power of line on the B1 bus in the normal SSSC mode. $\mathrm{P}$ is active power, shown by solid line, $\mathrm{Q}$ is reactive power, shown by dashed line, $\mathrm{T}$ is device operation time. 


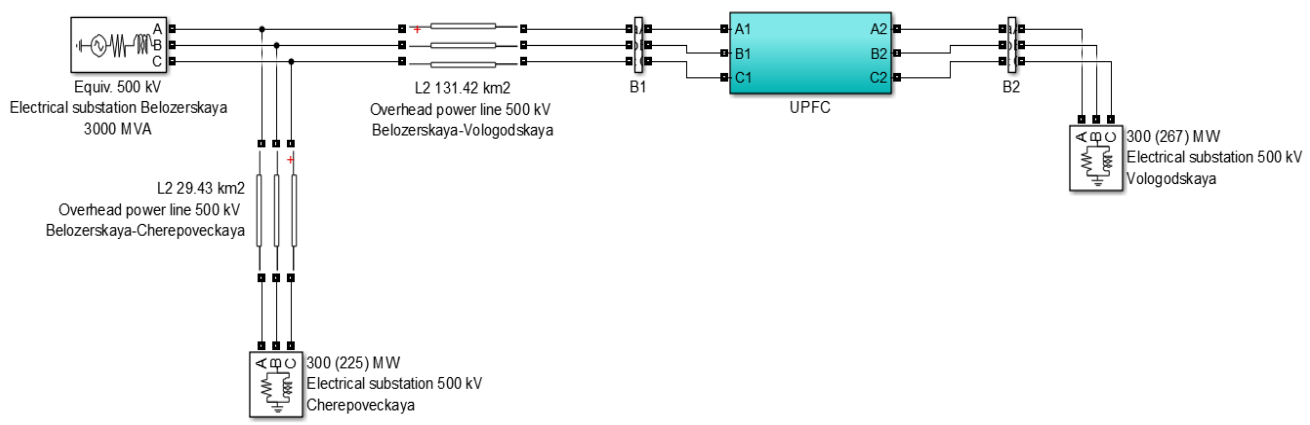

Fig. 7. Model of 500 kV SS Belozerskaya - SS Vologodskaya power system with UPFC device.

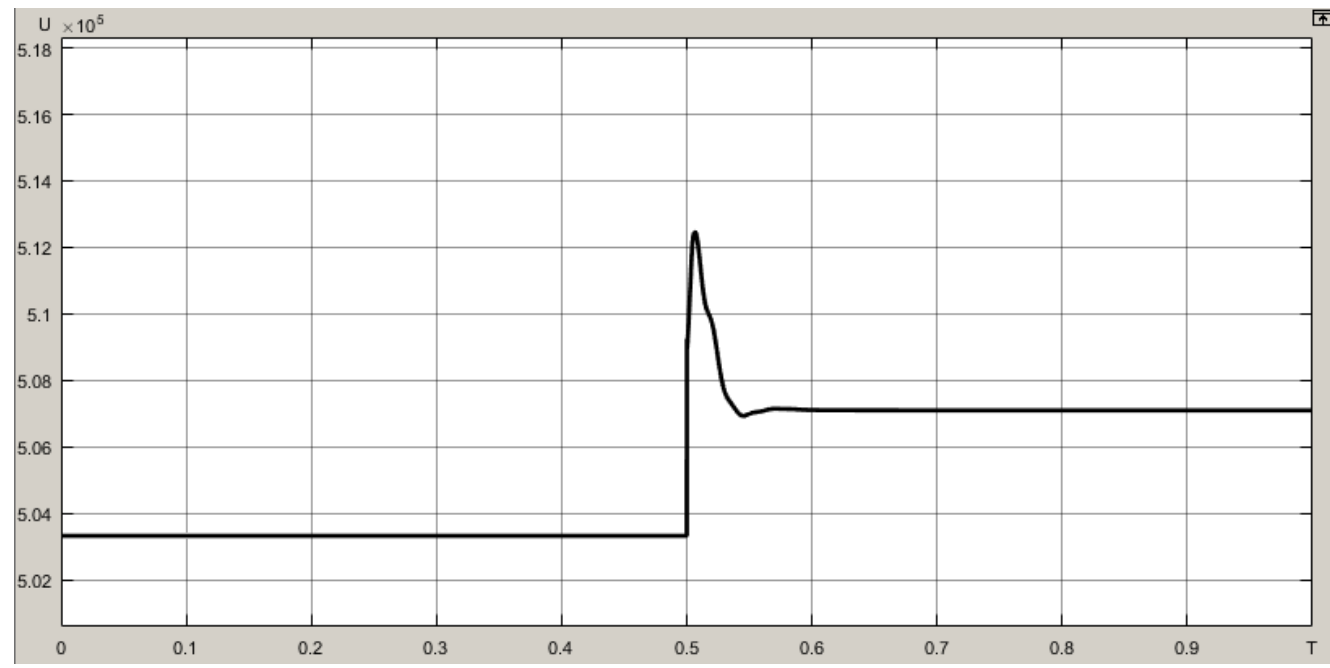

Fig. 8. Voltage on bus B1 with UPFC device. $\mathrm{U}$ is voltage on line, $\mathrm{T}$ is device operation time.

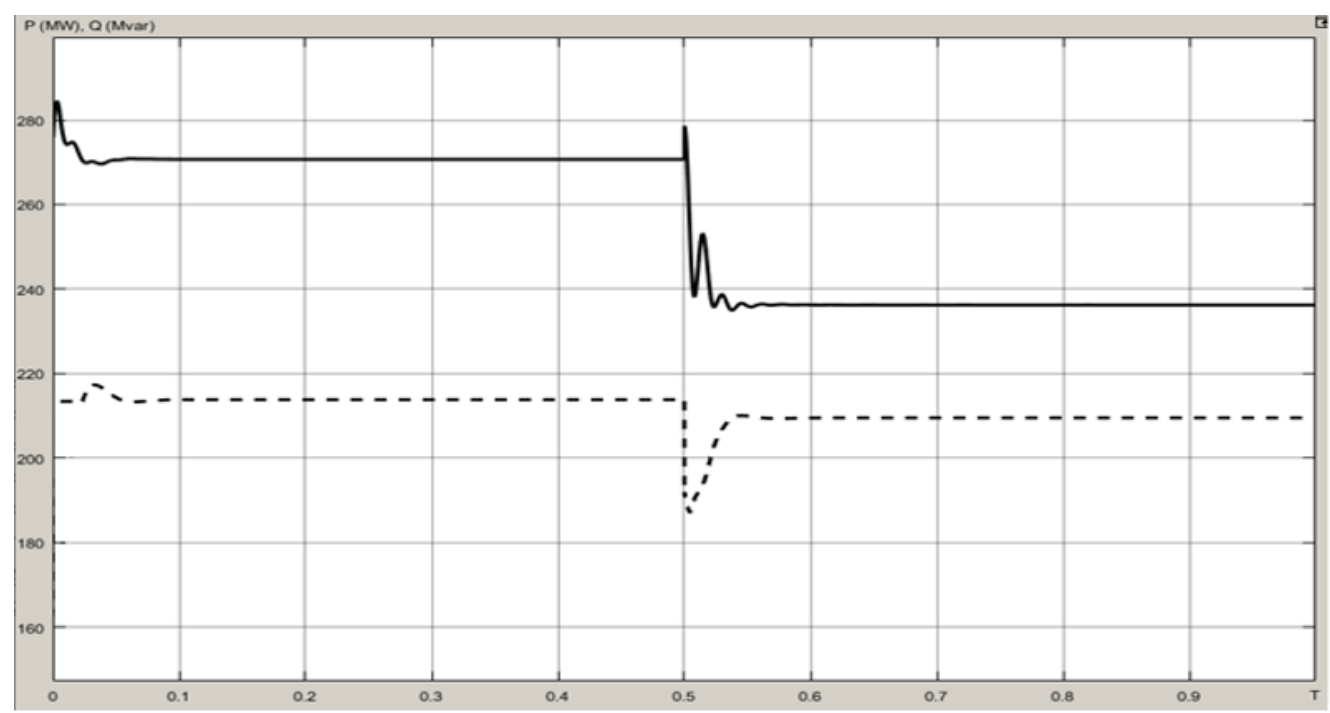

Fig. 9. Active and reactive power of line on the B1 bus in the normal UPFC mode. $\mathrm{P}$ is active power, shown by solid line, $\mathrm{Q}$ is reactive power, shown by dashed line, $\mathrm{T}$ is device operation time.

power from the network in exactly the same amount in which STATCOM gives (or receives) it [8]. Therefore, when active power in the system increases, the reactive power also increases. This can be seen from Figs. 8 and 9. At $\mathrm{t}=0-0.5 \mathrm{~s}$, voltage decreases accompanied with an increase in reactive and active power in the network. At $\mathrm{t}=0.5-1 \mathrm{~s}$, the device increases voltage, lowers the reactive power together with the active one and takes part of energy for auxiliary power supply system. 
Table 4. Comparison of $\mathrm{Q}$ and $\mathrm{P}$ on bus $\mathrm{B} 1$ of FACTS devices.

\begin{tabular}{|l|c|c|c|c|c|c|}
\hline $\begin{array}{l}\text { FACTS operation } \\
\text { mode }\end{array}$ & $\begin{array}{c}\text { Q, Mvar } \\
\text { STATCOM }\end{array}$ & $\begin{array}{c}\text { P, MW } \\
\text { STATCOM }\end{array}$ & $\begin{array}{c}\text { Q, Mvar } \\
\text { SSSC }\end{array}$ & $\begin{array}{c}\text { P, MW } \\
\text { SSSC }\end{array}$ & $\begin{array}{c}\text { Q, Mvar } \\
\text { UPFC }\end{array}$ & $\begin{array}{c}\text { P, MW } \\
\text { UPFC }\end{array}$ \\
\hline Switched off & 215 & 275 & 196 & 275 & 215 & 270 \\
\hline Undervoltage mode & 276 & 254 & 204 & 250 & 215 & 270 \\
\hline Overvoltage mode & 105 & 302 & 187 & 302 & 210 & 238 \\
\hline Average value & 190.5 & 278 & 195.5 & 276 & 212.5 & 254 \\
\hline
\end{tabular}

\section{Conclusion}

The conducted modeling shows that each FACTS device compensates reactive power in different ways. The values given in Tables allow one to choose the best compensation for the $500 \mathrm{kV}$ line SS Belozerskaya - SS Vologodskaya. Since power compensation includes increasing the active power in network and decreasing the reactive power, the smallest lost power and the greatest transmitted power can be considered as criterion for selection of the most suitable option. The results of modeling were used to calculate the average values of reactive and active power, which are shown in Table 4.

This table can be used to analyze the efficiency of each device relative to the normal operating mode of system and select the best of them. STATCOM can reduce the loss of reactive power on line by 24.5 Mvar and increase the active power by $3 \mathrm{MW}$. SSSC reduces losses by $0.5 \mathrm{Mvar}$ and increases active power by $1 \mathrm{MW}$. UPFC enables to reduce reactive power by 2.5 Mvar, and to reduce useful power by $16 \mathrm{MW}$. The obtained data show that STATCOM is the best choice for installation on the line, since it best reduces reactive power and increases active power.

\section{References}

[1] A. Udaratin, A. Alyunov, A. Krutikov, L.R. Mukhametova, O.O. Zaripov, I.V. Bochkarev, E3S Web of Conferences 124, 02020 (2019).

[2] A. Nemirovskiy, A. Kashin, V. Kosmach, Y. Titovec, I. Toptygin, D. Zaripova, IOP Conference Series: Earth and Environmental Science (EES) 337, 1, 012071 (2019).

[3] A. Ydaratin, T. Akhmetov, S. Makoev, IJCIET 10, 2, (2019).

[4] V. Zhukov, A. Shmelev, D. Mikheev, Russian Electrical Engineering 89, 5 (2018).

[5] M. Bashirov, A. Khismatullin, E. Sirotina, LNEE 641, 613-621 (2020).

[6] S. Tsyruk, S. Gamazin, Y. Ryzhkova, K. Charafeddine, Dynamics, 8601484 (2019).

[7] V. Kozlovsky, S. Petrovsky, V. Vakhnina, D. Skripnuk, EIConRus, 8657322, 569-573 (2019).

[8] D. Aydarov, V. Kozlovsky, V. Vakhnina, S. Kleymenov, N. Didenko, EIConRus, 8656815, 416-419 (2019). 